\title{
Veganism as Affirmative Biopolitics: Moving Towards A Posthumanist Ethics?
}

\author{
Eva Giraud
}

Animal studies, as an academic field, emerged from a conceptual and political demand to re-evaluate (and potentially contest) existing human-animal relations, by creating new ethical frameworks that do not automatically privilege the human. ${ }^{1}$ Recent theoretical trends in the field, however, have led to criticisms that it has betrayed this original aim. The most pointed criticism is that the field's engagement with posthumanist concepts, which ostensibly de-centre the human and dislodge the epistemological structures of humanist thought, have (paradoxically) resulted in the emergence of a new, subtle form of anthropocentrism that is difficult to challenge. ${ }^{2}$ Thinkers from Critical Animal Studies (CAS), for instance, have suggested that influential theorists, such as Donna Haraway, have led to the depoliticization of animal studies by leaving cultural practices that treat animals as "legitimately" exploitable intact (including meat consumption and animal breeding), while displacing the conceptual frameworks that have conventionally been used to contest these practices (namely animal rights discourses). ${ }^{3}$ The problem is that critical arguments such as this tend to be by-passed without full consideration. Thinkers from the wider field of animal studies, for instance, have argued that CAS perspectives are grounded in totalising rights discourses, which derive from a humanist lineage and are thus intrinsically anthropocentric, undercutting their intended purpose. ${ }^{4}$ In sum, these debates have resulted in tensions between "mainstream" and critical animal studies, which hinge on questions of rights. 
On the one hand, "mainstream" animal studies have increasingly taken up theoretical frameworks from posthumanist thought; they argue that appeals to animal rights are selfdefeating because they reinforce ethical frameworks that privilege the human. On the other hand, CAS thinkers warn of the danger of sacrificing concrete action and clear ethical frameworks in favour of the apolitical theoretical conjecture that they attribute to posthumanism. ${ }^{5}$

As I have argued elsewhere, navigating these tensions is a politically urgent task due to the relationship between material forms of exploitation, the ethical frameworks that legitimise this exploitation and the epistemological categories that underpin this ethics (such as the absolute distinctions between human and animal that are central to liberal-humanism). ${ }^{6}$ Within animal studies posthumanism has been valuable in contesting the centrality of the human as the locus for ethics, with some of the field's most innovative and influential work employing posthumanist theory to create radical ways of conceptualising human-animal relations. ${ }^{7}$ As touched on above, the problem is that posthumanism simultaneously enables a less visible form of anthropocentrism to persist within animal studies while also making it difficult to challenge this anthropocentrism using conventional frameworks (such as rights). It is becoming increasingly important, therefore, to develop an ethics that reconciles the politically productive elements of posthumanist thought with the critique of exploitation offered by CAS, in order to develop a non-anthropocentric ethics that also preserves space for political critique.

I approach this task through building on work by thinkers who have attempted to generate dialogue between posthumanism and critical animal studies (such as Helena Pedersen and Richard Twine, in addition to my own work), with a specific focus on how these debates have played out around the issue of veganism as a cultural practice. Initially I flesh out the relationship not only between mainstream animal studies and CAS but also ecofeminism, as its 
influence on these other fields makes it valuable for grasping how theoretical debates surrounding veganism have manifested themselves in the academic context where they initially came to the fore. I then argue that Cary Wolfe's recent posthumanist analysis of meat consumption offers a useful means of reconciling insights from these often antagonistic perspectives. Bringing these fields together is, in part, a response to Greta Gaard's argument that: "the animal studies groundwork of vegan feminists and ecofeminists is barely mentioned in the currently celebrated field of posthumanism, yet feminist scholarship both predates and helpfully complicates that work" ("New Directions for Ecofeminism", 3). Creating this conversation, however, is also valuable in foregrounding how praxis criticised by "mainstream" animal studies (such vegan politics), needs to be taken more seriously as a critical-theoretical tool with the power to both unsettle material forms of exploitation and the humanist epistemologies that provide ethical legitimation for these practices. More broadly, my argument is that Wolfe's work is valuable in creating space for a critical-posthumanist politics which draws together insights from CAS, posthumanism and ecofeminism.

Before turning to ecofeminism and exploring the value of Wolfe in more depth, however, it is useful to provide a brief overview of some of the wider debates surrounding veganism and of the concepts central to Wolfe's work.

\section{Vegan Debates}

Veganism is becoming a prominent area of focus in contemporary cultural theory because debates about vegan praxis have emerged as a sub-field of animal studies that crystallises tensions between CAS and posthumanist-inflected "mainstream" animal studies. By grounding itself in notions of the inviolable rights of animals (at least from the perspective of thinkers such 
as Haraway, who will be focused on here due to her influence in animal studies), veganism seems to be underpinned by the humanist ethical frameworks that mainstream animal studies is moving away from in its turn to posthumanism. ${ }^{8}$ An alternative body of theoretical work, however, offers a different perspective on veganism, positioning it as a practice that disrupts humanist logic by displacing the structural position of the animal as legitimately "consumable" (i.e. as entities that can be eaten without ethical reflection). Pedersen, for instance, initiates a conversation between CAS and posthumanism, citing Carol Adams's argument that posthumanist relations towards animals end at the moment of consuming animal products: "the autonomous, unitary human fades in the presence of postmodernism, except at a meal" (Adams in Pedersen, 75). ${ }^{9}$ For both Pedersen and Adams, meat-consumption is a reinstatement of humanist logic as:

All structures, flows, norms, relations, and other discursive and material conditions necessary to perpetuate the global institution of meat are already in place, and working ceaselessly [at the moment of consumption]. However, if not only subjectivities, but also power relations are understood as organic, dynamic, genuinely unstable ecologies, why not use the open-ended indeterminacy of posthumanism to radically transform our consumption referents, theories and practices? (Pedersen, 75)

Pedersen's argument is that veganism—rather than reinforcing humanism—can unsettle human privilege by undermining the consumer/consumed relation: "the vegan impulse can have profound effects on human-animal relationships as one among other transformative moves in a posthumanist era" (75).

The problem is that such arguments often stem from debates within ecofeminism or CAS that are "short-circuited," that is, dismissed without due consideration because of their perceived liberal-humanist grounding in "mainstream" animal studies contexts. More specifically, the dismissal of these arguments is due to their being perceived as grounded in emotive responses to 
meat-consumption which have led to humans wanting to become advocates for the animals they perceive as being exploited. This appeal to emotion, therefore, appears to contrast with the radically non-anthropocentric critique of human-animal relations offered by posthumanism. ${ }^{10}$ To combat this (often misguided) framing of critical perspectives as emotive or seeking purely to represent others, it is therefore necessary to advance Pedersen's argument about the value of vegan praxis to posthumanism. To do this I will develop her claims about the epistemological significance of veganism as something with the potential to complicate and enhance a nonanthropocentric ethics, before turning to Cary Wolfe's work as a means of productively framing these arguments in relation to posthumanist thought.

\section{Wolfe's Affirmative Biopolitics}

Wolfe's analysis of the persistence of humanist values in the agricultural-industrial complex consolidates the nuanced account of the epistemological significance of veganism, which is hinted at by Pedersen. Developing his work as a theoretical framework, I argue that veganism does not have to be grounded in humanist values but can function as an affirmative biopolitics that challenges the biopolitical dispositifs which render animals exploitable. ${ }^{11}$ These concepts will be explored in more depth shortly but, essentially, his account of biopolitics analyses the processes through which biopower is exercised-or the subtle mechanisms through which power is exerted over life itself - particularly within the agricultural-industrial complex, where both human and animal life is carefully regulated to maximise its productivity. He makes explicit, however, that describing this exertion of biopower as biopolitical is vital in opening space for resistance, by underlining that it is not an all-pervasive process but something that occurs through specific cultural and political mechanisms that can be challenged. Where this 
argument is valuable in bridging CAS and "mainstream" animal studies is in including animals as biopolitical subjects. His affirmative biopolitics foregrounds that biopower relies on the species divide both symbolically ("animalizing” different social groups to provide ethical justification for their exploitation) and materially (as with the regulation of human and animal bodies in the agricultural-industrial complex). This perspective, therefore, affirms the connections between human and animal exploitation through including animals as subjects of biopower. The significance of this argument is not only that the intersections between human and animal exploitation mean neither can be challenged in isolation but, more than this, that affirming animals' role within contemporary biopolitics is vital in strengthening potential for resistance: "[it is necessary to] include nonhuman animals as coconstitutive with human beings in resisting the articulations of a biopolitical dispositif in and through the body" (Before the Law, 27). ${ }^{12}$ By framing veganism as a form of affirmative biopolitics, I suggest that it has the capacity to not only challenge the cultural positioning of animals as exploitable but to unsettle the epistemological categories that legitimises this exploitation.

Before developing these arguments, however, it is necessary to gain further insight into why veganism has been associated with humanist logic, by mapping some of the debates between CAS, ecofeminism and mainstream animal studies.

\section{Veganism as Intersectional Praxis?}

Veganism is used here to refer to the practice of eschewing all animal products, including clothing and products made from animal-derived materials, as well as the consumption of foods such as meat, dairy, eggs and honey. Though variants of a vegan diet had long been adhered to by branches of certain religions (notably particular strands of Buddhism and Hinduism), the term 
itself was coined in 1944 with the launch of the Vegan Society and in recent years has been the focus of academic study due to its association with radical politics. ${ }^{13}$ More specifically, I am referring to veganism that is grounded in a concern with animal ethics (rather than in reference to vegan diets that have been adopted by necessity, geographical constraints or for religious or other political purposes), as this form of ethical veganism is what has been central to discussions within CAS, ecofeminism and grassroots activist praxis.

What is emphasised in CAS and ecofeminism (but often overlooked) is that this form of ethical veganism has both material and symbolic significance, as with Pedersen's argument that veganism can challenge the epistemological hierarchies associated with humanism and its privileging particular types of political subject (for further expansion of this line of argument, see Giraud "Beasts of Burden"). For instance, the series of binary oppositions that posthumanism seeks to challenge — such as human/animal, culture/nature, subject/object—which the humanist subject has conventionally been defined against, ${ }^{14}$ could potentially be unsettled by practices that both focus ethical attention on the subaltern term in these pairings and challenge the positioning of this term as subaltern. Understood in this light, veganism's refusal to position animals as "consumable" could therefore be understood as a material-semiotic challenge to the epistemological frameworks that short-circuit ethical reflection on animal consumption (by treating human privilege as a given). It is this epistemologically disruptive framing of veganism that will be focused on here, due to its centrality to discussions within ecofeminism, CAS and debates that straddle the two fields.

To contextualise this framing of veganism as "disruptive" it is useful to turn to thinkers from CAS such as Richard Twine, who argue that the category "animal" has a unique role in sustaining humanist epistemologies, by not only providing ethical sanction for animal 
exploitation but by underpinning conceptual structures that legitimise other forms of exploitation. He argues that a critique of speciesism can enhance intersectional feminist politics through making a "specific contribution that argues that categories such as gender, class and race are infused with the human-animal distinction"; a model "predicated on a generalised opposition to 'animal' and 'nature"' (Animals as Biotechnology, 10). Crucially, Twine also emphasises the way the human-animal distinction is also used to produce an "internal nature" (or animality) that is deployed in order to frame certain human characteristics as undesirable and requiring elimination or careful regulation (a process that can, similarly, be used to engineer the marginalisation of certain social groups).

These perspectives therefore dovetail with arguments that have proven influential within animal studies more broadly, notably Jacques Derrida's insistence on the human/animal dichotomy as underpinning other problematic binaries, an argument that has been taken up in Wolfe's account of biopolitics as well by Matthew Calarco. In addition, these ideas resonate with theorists such as Giorgio Agamben, whose "anthropological machine" (as set out in The Open) illustrates the production of animality on two levels: the external production of an animality against which the autonomous humanist subject is defined, and an internal animality that is produced by certain traits being identified as "animal-like." As Andrew Benjamin argues, this allows the category "animal" to both be projected onto certain social groups, as well as certain physical or cultural traits to be isolated in individuals and identified as problematic and requiring management (Benjamin, 60). The political significance of these debates is identified by Wolfe, who argues that a fundamental challenge to the category "animal" (as offered by posthumanist thought) is vital in preventing this category from being projected onto other social groups (Before the Law, 10). Understood in this light, practices such as veganism could be understood as 
having intersectional significance due to their ability to unsettle the way that the category “animal" can be used to designate certain groups of actors as "legitimately" exploitable.

\section{Veganism as Totalising Imperative?}

Veganism, however, has been interpreted in the opposite way by thinkers within animal studies. Haraway, for instance, suggests it is a totalising moral imperative:

Try as we might to distance ourselves, there is no way of living that is not also a way of someone, not just something, else dying differentially. Vegans come as close as anyone, and their work to avoid eating or wearing any animal products would consign most domestic animals to the status of curated heritage or to just plain extermination as kinds and as individuals. ${ }^{15} \mathrm{I}$ do not disagree that vegetarianism, veganism, and opposition to sentient animal experimentation can be powerful feminist positions; I do disagree that they are feminist Doxa ... It is not killing that gets us into exterminism, but making things killable. (80)

This resonates with wider theoretical trends focused on de-centring the human, such as the rise of object-oriented ontology. Ian Bogost's Alien Phenomenology, for instance, argues that veganism involves the projection of human ideas onto non-human entities by making presumptions about what animals "want": "the assumption that the rights any thing should have are the same ones we believe we should have; that living things more like us are more important than those less like us" (73). This framing of veganism, therefore, positions it as contrary to the demands of theories seeking to de-centre the human. Similarly, in What Is Posthumanism? Wolfe suggests that a complete de-centring of the human does not just necessitate challenging human privilege, but requires a displacement of the knowing theorist. For this reason, he argues that animal rights philosophers are only partially posthumanist, as they might challenge the cultural positioning of animals as exploitable but leave the epistemological structures that legitimise this exploitation intact through their own positioning as all-knowing observer of an objective reality (What Is 
Posthumanism, 117). For Wolfe, such a perspective reinforces the subject/object dualism that maps onto human/animal dichotomies. Theories or practices that have this dynamic, therefore, undercut their own aims through reinforcing the epistemological foundations of humanism even as they attempt to contest its cultural effects.

It is exactly this problem which leads Haraway to condemn practices such as veganism, arguing that they rely on a "god-trick of self-certainty" (or the sense that they are indisputably ethically correct) by grounding themselves in notions of inviolable animal rights (When Species Meet, 88-9). Similarly, Jamie Lorimer's otherwise useful overview of recent trends in cultural geography makes a negative comparison between what he describes as the "context-specific forms of posthumanist ethical and political responsibility" of animal studies, and more critical perspectives offered by CAS "which grounds its appeals for animal rights on the comparable existence of essential human characteristics in non-humans" (604). ${ }^{16}$ In summary, therefore, more critical perspectives have been condemned for their failure to challenge humanist epistemologies, with practices such as veganism seen as firmly centring the human as the one bestowing "rights" to animals through (to cite Haraway's argument) extending blanket laws such as "thou shalt not kill" to animals (When Species Meet, 80).

This framing of veganism as totalising is also connected with a wider suspicion of deep ecology, with which animal rights praxis frequently associated (an association that masks the more complex evolution of vegan studies within ecological critique). For instance, Wolfe's Animal Rites begins by delineating some of the criticisms levelled at deep ecology, both for its perceived totalitarian approach towards politics (in prohibiting human actions that impinge on nature) and for its "soft anthropocentrism" in attributing "human qualities, and ... at least somewhat human statutes, to the nonhuman realm of nature" $(26) .{ }^{17}$ Similarly, the separation 
between nature and culture that underpins deep ecology (in the name of preserving untouched nature from human activity) has been criticised for perpetuating the nature/culture dichotomy in a way that reinstates the binaries of humanist logic. Haraway has also condemned deep ecological approaches in her 1992 essay, "The Promises of Monsters.” warning that "nature's discursive constitution as 'other' in the histories of colonialism, racism, sexism, and class domination of many kinds" is in danger of being reproduced by deep ecological discourses (296). As touched on above, veganism is framed for Haraway in a similar manner: as a totalising, prohibitory imperative.

\section{Vegan Debates in Ecofeminism}

Similar debates have emerged in ecofeminist contexts, indeed, one of the most important contributions of ecofeminism has been its critique of deep ecology for its ethnocentrism as well as its appeal to dualisms (Seager, 168). As a result, veganism has been a contentious topic within ecofeminism, with some thinkers (notably Val Plumwood) framing it as part of this totalising lineage and criticising veganism's use as a universal ethical standard for being "culturally ethnocentric and dualistic" (Sturgeon, 154). Twine foregrounds these tensions, mapping out debates between thinkers such as Carol Adams and Kathryn Paxton George that centre on the relationship between feminism and vegetarianism (Twine "Intersectional Disgust", 400). For Twine, however, these tensions only arise due to certain interlocutors in the debate (those suspicious of a vegan-feminist politics, such as George) accepting the human/animal dichotomy, which leads them to perceive an intersectional politics as implying women are somehow "like" animals. In contrast, he suggests that focusing ethical attention on the animal actually lends support to a feminist politics by challenging the epistemological structures that support 
patriarchy (an argument reiterated by Gaard's overviews of the field, "Ecofeminism Revisited" and "Vegetarian Feminism").

This argument is consolidated by Marti Kheel, whose understanding of veganism is akin to Pedersen's framing of the practice, as she counters its portrayal as a totalising imperative by emphasising its epistemologically disruptive role. For Kheel, veganism does not mark the imposition of a new set of norms, but is conceptually valuable in highlighting the normative cultural positioning of animals as "exploitable" that is reinforced materially through everyday practices of consumption: "although ecofeminism may not support the case for vegetarianism as a universal dietary norm, it may, nonetheless, help to dislodge the conceptual substructures that support the practice of meat-eating" (329). What Kheel offers is an "invitational approach" to vegetarianism, which recognizes "that the subject of meat eating differs across boundaries of culture, race, gender and class. It acknowledges that there might be limiting factors, such as geography and climate, which preclude the possibility of eating a vegetarian diet for some people" (335). She maintains, nonetheless, that such an acknowledgement does not preclude culturally specific analyses that examine the structural function of meat eating to explore how it reinforces context-specific power relations.

This brief overview of ecofeminist debates illustrates why thinkers within CAS have found ecofeminism particularly useful in providing a rich site for thinking through intersections between human and animal exploitation, as evidenced by Twine's engagement with intersectional vegetarian-feminist thought, or Pedersen's use of Carol Adams. In analysing these debates I have also pointed towards productive relationships that could be had between more critical approaches to human-animal relations (such as vegan praxis) and posthumanist thought, due to this emphasis on the conceptually disruptive potential of veganism. At present, however, 
these engagements have failed to fully materialise due to the tensions that exist between posthumanism and CAS, which now need to be mapped out in more detail.

\section{Theoretical Short Circuits}

Both CAS theorists and thinkers informed by ecofeminism who advocate veganism face a difficult task: overcoming attempts to short-circuit, or dismiss out of hand, their perspective by portraying it as totalising. Yet - in apparent contradiction to this - they must also overcome being framed as motivated purely by the emotional, embodied dimension of animal consumption. As touched on above, for instance, Haraway is suspicious of vegan praxis for being totalising, but she also attributes thinkers such as Adams', as well as Lynda Birke and Marc Bekoff's, vegan stance as being due to their "love of animals" (When Species Meet, 299). Vegan praxis is thus simultaneously cast as totalising and individualising, with critical perspectives faced with defending themselves against contradictory arguments.

These criticisms, however, are made possible due to certain strategies adopted within ecofeminism itself. Kheel, for instance, argues against Plumwood's presumption "that the avoidance of flesh foods is based on an abstract philosophical viewpoint" by emphasising the value of "a visceral repugnance to the idea of the suffering and death of nonhuman animals" (336). This assertion is intended to point towards the material-semiotic function of veganism as a concrete practice that also unsettles epistemological dichotomies, yet unfortunately feeds into discourses that have been used to misrepresent ecofeminist critique as grounded in a romanticised, and ultimately essentialising, view of nature. Greta Gaard, for instance, suggests that thinkers have frequently distanced themselves from the ecofeminist label due to fear of “contamination-by-association" (Gaard, "Ecofeminism Revisited," 27). Combating this claim 
she argues that ecofeminism actually shares the same epistemological project as posthumanist thought, but this insight has been lost because "poststructuralist and other third-wave feminisms portrayed all ecofeminisms as an exclusively essentialist equation of women with nature, discrediting ecofeminism's diversity of arguments and standpoints" (Gaard, 27). Indeed, in an earlier essay she counters this portrayal of ecofeminism by emphasising the simultaneous structural critique of humanist epistemologies that is integral to this field of thought, foregrounding how its critique of animal liberation theorists such as Peter Singer and Tom Regan stems from the way their work "perpetuates 'an unnecessary dichotomy' between reason and emotion when both offer valuable information in the process of ethical decision making" ("Vegetarian Ecofeminism," 123). These arguments build on the feminist project of challenging the reason/emotion dichotomy (which also resonates within Haraway's own work), but the problem is that when these debates are translated to "mainstream" animal studies their value as a platform for more sustained critique is undermined. As touched on earlier (see note 4), this is illustrated by Haraway framing of Adams's vegan-feminist critique of meat-consumption as simply a personal decision (grounded in her "love" for animals).

Despite being misrepresented as purely emotive, ironically the approach taken by thinkers such as Kheel actually mirrors strategies deployed within "mainstream" animal studies. To again draw on Lorimer's characterisation, animal studies is constantly forced to balance the posthumanist demand to move beyond "the hard fought taxonomies of modern legislation and representation" with the task of developing an ethics derived from context-specific interactions with "more-than-human" actors (604). These tensions are epitomised by the work of Haraway. On the one hand, her focus on complex, irreducible relationships between human and non-human actors has led to a critique of conventional advocacy frameworks for projecting categories 
couched in humanist values (such as rights) onto animals (as argued in her 2011 essay "Species Matters"). On the other hand, this leads to the problems identified by Lorimer of such approaches being "vague and context-specific. They do not offer general ethical frameworks or overarching structural causes" (604). Moreover, Lorimer suggests that this refusal to develop a broader ethical framework results in a new set of theoretical norms, grounded in "an admonishment of actions that constrain the lively potential of evolving ecologies" (601). ${ }^{18}$ This is explicit in Haraway, who systematically condemns approaches (from deep-ecology to vegan praxis) that she sees as constraining certain forms of "intra-action" or shutting down “cosmopolitical risk." ${ }^{\prime 19}$ I argue, however, (in line with Lorimer's warnings) that this mode of posthumanist ethics can be as totalising as the perspectives Haraway dismisses, yet its totalising nature is masked by the normativity of the cultural practices that this line of argument is used to defend. This is because posthumanist theory has been increasingly used as a symbolically violent tool within mainstream animal studies, as it allows criticism of practices (such as food production, animal research, and dog breeding) to be framed as stemming from liberal-humanist values that are incompatible with a non-anthropocentric ethics. By positioning these criticisms as out of joint with the dominant paradigm of animal studies, however, this dismissal seems acceptable within the terms of the field, which means that criticisms are short-circuited before they can be addressed.

This problem is particularly pronounced in relation to debates surrounding veganism, with the practice portrayed as a totalising perspective privileging the individual (thus inadvertently humanist and anthropocentric). In contrast, meat consumption is framed as one of many ways of relating to non-human actors that could emerge out of complex political ecologies. ${ }^{20}$ The only way that veganism can be positioned as totalising in comparison with animal consumption, 
however, is if meat-eating itself is positioned as normative and disassociated from its cultural context. My argument is that unsettling the cultural assumptions that frame these debates is where Wolfe's work becomes particularly useful. Before the Law, for instance, adds a new dimension to arguments about meat consumption, by illustrating how eating animals itself could be seen as a totalising stance by positioning animals as legitimately exploitable, in both factory farming and individualised contexts (such as hunting). It is important, therefore, to develop this analysis further in order to challenge the automatic dismissal of vegan perspectives as totalising, by demonstrating how the maintenance of categories such as "meat" performs an equally totalising function, reinstalling notions of the autonomous subject that critical posthumanism ostensibly moves beyond. Wolfe's work, therefore, lends epistemological support to the political debates that have persisted in ecofeminist discourse and CAS, creating space for (much needed) dialogue between these perspectives and posthumanism.

\section{Defending the Ethical Community}

Wolfe's recent work offers new insight into these issues by positioning the expansion of the ethical community to animals not as the projection of rights or the imposition of totalising values, but as an affirmative biopolitics that acknowledges the irreducible material and symbolic connections between human and animal exploitation and frames these connections as a potential site of resistance. This argument is complex and so requires unpacking at this juncture, particularly the relationship between species, biopolitics and membership of an ethical community.

Before the Law historicizes biopower, pointing to its contemporary role in supporting biocapitalism. Wolfe argues that control over animal life and death no longer take a sacrificial 
form (where a sovereign decision is made over the life and death of certain actors or groups of actors, as is portrayed for instance in the work of Agamben), but is entirely routinized via the factory farming system. On a superficial level, this argument coheres with Haraway's critique of the act of "making killable," where she argues that killing in itself is not the problem but the act of rendering whole categories of beings legitimately "killable" (or at any rate exploitable; When Species Meet, 80). This is supported by Wolfe's argument that the concept of species has the function of legitimising "indirect murder," in contemporary biopolitical contexts, through framing certain forms of killing as ethically acceptable. Moreover, he suggests that the categorization of certain actors (both human and non-human) as legitimately exploitable on a large scale, which occurs within the agricultural-industrial complex, has acted as a testing ground for the techniques of biopower:

Such practices must be seen not just as political but as in fact constitutively political for biopolitics in its modern form. Indeed the practices of maximizing control over life and death, of 'making live', in Foucault's words, through eugenics, artificial insemination and selective breeding, pharmaceutical enhancement, inoculation and the like, are on display in the modern factory farm as perhaps nowhere else in biopolitical history. (Before the Law, 46)

"Species" thus functions to separate actors who are legitimately "killable" from those who are not and, perhaps still more seriously, de-politicizes these acts of killing; making it impossible to ask ethical questions about them. This is deeply problematic for two reasons: firstly, it secures an epistemological mechanism that allows animality to be projected onto certain social groups, whenever it is politically expedient to disregard their rights (as touched on previously); secondly, the failure to understand such acts of killing as political means that it is impossible to disrupt the mechanisms of biopower that enact this killing. 
This systematic exclusion of certain actors from ethical consideration is in stark contrast to the way that other forms of political subjectivity have their rights privileged, such as the liberalindividualist subject whose rights are protected at all costs (due to being integral to the current power regime). ${ }^{21}$ To understand how this uneven distribution of "rights" occurs in practice, Wolfe focuses on the law due to it being a privileged site for determining who (or what) counts both politically and epistemologically. Throughout his arguments Wolfe fleshes out the relationship between the contemporary legal system and the autonomous liberal-individualist subject, describing how the law functions to protect the sovereignty of this subject. At stake in questions about who is afforded legal protection, are issues of:

...sovereignty in several different registers - not just of the nation-state but of the family, the familiar, the domestic, the "proper" to man, the oikos of the ecological, the economic, the ethos and the place of dwelling, of that which is "ours" or "mine" and deserves immunitary protection. All of these are iterations of the "ipesity" of the autonomous subject. (95)

The law, therefore, at present reinforces the ipesity or sovereign "wholeness" of the subject, through protecting them against anything that could impinge on this autonomy. As Wolfe argues, however, this subject itself is defined via excluding the animal: "Ipseity and sovereignty are taken to be in stark opposition to the 'animal' and to the animality of the human when the human becomes something anonymous" (5). On a more collective level, the level of law that has to protect the rights of a range of subjects, this inclusion/exclusion occurs through certain actors being seen as part of the ethical community and others being outside of it (with the human/animal distinction again delineating the boundaries of this community). The law, therefore, protects certain ethical communities via what Wolfe (drawing on Esposito, Derrida, and Luhmann) describes as an "immunitary" function for society" (90), it defends against 
anything that might threaten the autonomy of its subjects by denying ethical responsibility to actors that could damage their freedom.

\section{Expanding the Ethical Community}

What Before the Law grapples with, and where it opens up space for dialogue between more critical perspectives and mainstream animal studies, is how to afford non-human animals ethical consideration. This is a necessary political task in light of Wolfe's analysis of biopolitics, but a difficult task in light of his discussion of the functioning of the law. Crudely put, the issue is where to draw the line. A simple solution (and the one ostensibly advocated by animal rights advocates) might be to simply extend the boundaries of the ethical community to animals. This notion, however, has been contested for a variety of reasons: Haraway, for instance, argues in When Species Meet that killing is unavoidable within any form of agriculture (80). In "Jumping Hurdles with Mosquitos" Uli Beisel raises more pointed questions of how an ethics predicated on not killing can be reconciled with the very material dangers of certain non-human actors—such as mosquitos or viruses - to the lives of other actors. ${ }^{22}$ The key issue highlighted by these questions from an epistemological perspective, therefore, is that it is impossible to simply include animals into the ethical community while simultaneously de-centring the human, as context-specific decisions always need to be made about which type of animals are part of this community. The problem is that this requires an external observer making a decision about who belongs to this community and is therefore a process that necessitates some form of totalising judgement (thus reinstalling the epistemological structures that privilege the human, which Wolfe is attempting to move beyond in his account of posthumanism and Haraway condemns in her analysis of human-animal relations). 
Theoretical issues relating to this difficulty are raised by Wolfe, when he interrogates Esposito's solution to the problem: including all "life" as part of the ethical community. For Esposito, "a turn away from the thanontological and autoimmunitary logic of biopolitics can only take place if life as such—not just human (vs animal) life ... becomes the subject of immunitary protection" (Wolfe, Before the Law, 55). The problem with this is again that "undifferentiated life" includes also those actors that are potentially threatening to the integrity of other actors. The way this has been resolved for Esposito (and to an extent Haraway) is via notions of flourishing developed from ecofeminism. Haraway derives her own notion of flourishing from Chris Cuomo's argument that: “Assessing actions, practices, institutions, attitudes and values in terms of their impact on ecological and human flourishing" could be a useful beginning for a nonanthropocentric ethics (Cuomo, 65). This is interpreted by Haraway as asking questions such as:

What do they [the actors at stake] contribute to the flourishing and health of the land and its critters ... ? That question does not invite a disengaged "liberal" ethics or politics but requires examined lives that take risks to help the flourishing of some ways of getting on together and not others. (When Species Meet, 288)

For Esposito this manifests itself as attempting to maximise biodiversity, but, as Wolfe argues, this "means that rare species and endangered individuals are by definition more valuable than those that are more common," which creates unintentional hierarchies (Before the Law, 60). Such approaches also offer an ethics seemingly without closure which, though valuable from Haraway's perspective in "staying with the trouble" and refusing to shut down ways of relating, could lead to certain social actors taking advantage of this indistinct ethical framing: "A fluid political ecology without equilibrium is ideal for a capitalist Anthropocene to be governed by expanding markets in biodiversity..." (Lormier, 603). Wolfe compounds these issues in What is Postmodernism? in his critique of Martha Nussbaum's conceptions of flourishing, pointing out 
two central problems: "determining what counts as human flourishing" (and how this indeterminate label could include problematic actions that are normatively seen as the exercise of liberal-individualist rights) and "the unavoidability ... of falling into precisely what she criticizes in the utilitarians, namely, the problem of 'balancing' competing rights to 'flourishing' (human and nonhuman) just as the utilitarians must rank competing 'interests"” (67). Deciding not to kill animals, therefore, is a complex theoretical and practical question, due to raising issues of how this decision can be made without inadvertently reinstalling anthropocentric ethical structures.

\section{Creating Political Openness Through Ethical Closure}

To resolve this issue in his own work, Wolfe draws on the notion of "openness from closure": a concept derived from systems theory, which contends that entities can only connect or couple with their environment through ontological closure (What is Posthumanism?, 117). This might seem paradoxical, but what this closure achieves is the defining of an entity in such a way that fixed coordinates can be located to create points of connection, enabling "structured coupling" between an organism and its environment. For instance, a frog's pattern of behaviour and characteristics needs to be stable in order to establish a structured system of relationships with its environment. Connections with the external environment are created through the frog's clear definition as a specific type of organism, which open it to the complex structured patterns of interaction that are necessary for its subsistence within a particular eco-system. In What Is Postmodernism? Wolfe demonstrates the applicability of these arguments to other contexts, such as academic disciplines, arguing that disciplines need to have clearly defined boundaries in order to provide clear points of connection with other academic fields, and Before the Law sees Wolfe applying these arguments to the law itself, arguing that openness from closure is the mechanism 
that enables the law to operate. Again drawing on systems theorist Nikolas Luhmann, Wolfe frames the law as a self-referential, autopoietic system that functions according to pre-existing legal precedents and norms, as opposed to continually revising itself in line with new ethical insights: "This self-reference of the law's autopoiesis protects the communicative actions that take place in the legal domain from being steered or recoded by the moral distinction of 'right vs wrong"" (90). Closure from its ethical environment, therefore, allows the law to address issues of justice in a functional way, but in line with Wolfe's arguments about openness from closure, these clearly defined norms also enable the law to be open to future ethical shifts: "The inescapable self-referential closure of law is precisely, in its contingency, what opens it to the future and the outside, the as yet unaddressed subjects ... of justice" (92). What Wolfe means by this complex argument is that the clearly-defined ethical norms guiding the law can also make its ethical blind-spots explicit, creating spaces for connection with the broader environment as and when this environment shifts and falls into one of these blind-spots. This is evident, for instance, in contexts where new configurations of cultural actors lead to novel legal issues being raised that require resolution: "whenever the law grants new rights and duties, whenever it gives associations between humans and non-humans a legal voice, the law opens itself to the ecology of its broader environment" (Before the Law, 89).

This discussion of the law, therefore, goes back to the previous analysis of ethical communities and their immunitary relations with the outside world. Openness from closure in legal contexts points to the way that autoimmune protection afforded to legal subjects (via the automatic exclusion of certain actors from the ethical community) allows pragmatic ethical decisions to be made, while creating space for the possibility of the boundaries of the ethical community to shift and potentially include these actors in the future. This sounds paradoxical, 
but - again - having clearly defined boundaries is what makes the law's blind-spots visible when confronted with situations its current framework cannot encompass. For Wolfe, this is what "enables exposure to the other, to what and to who comes" (94).

\section{Veganism as Generating Openness from Closure}

An analysis of meat consumption can help to further illuminate this argument, due to Wolfe drawing on the practice to connect issues of humanist subjectivity, law and anthropocentric epistemologies. As touched on above, at present the law reinforces the subject's ipseity:

The specific role and character of industrially produced meat as a central element and tool in the biopolitical process of globalatinization, in which we find the "prosperity" and "well-being" of the subject-consumer channelled through not just the consumerist "choice" that capitalist globalization says it offers and on which it depends, but also through the complex psychodynamics and sacrifice and eating flesh as a sign of the subject's autonomy, security and "indemnification"... In other words "carnophallogocentrism" is a key export for the success of capitalist globalization, one bone on the backs of billions of dead animals. (100)

Wolfe's arguments, therefore, link the act of meat-consumption in the Global North (as opposed to the industrial processes underpinning it) to capitalist globalization. Here, his arguments intersect with a range of thinkers who have foregrounded the material and semiotic support animals lend to biocapitalism. Animal bodies are not just turned into biocapital, therefore, but act as a symbolic resource that depoliticises the biopolitical orchestration of mass-slaughter. ${ }^{23}$ This approach is in stark contrast with Haraway's analysis of meat consumption, which does not fully grapple with this symbolic dimension. In When Species Meet there is a contrast between her discussion of industrial farming processes (which she dismisses critically in the chapter "Chicken") versus complex 
relations that could occur between livestock and farmers or individual animals and hunters. Her final chapter, for instance, discusses the relationship between a colleague and the wild pigs he hunts: "His approach is resolutely tuned to ecological discourses, and he seems tone deaf to the demands individual animals might make as ventriloquized in rights idioms ... Adept hunters such as Lease treat pigs like wily animals with lives of their own" (298). Wolfe's arguments, however, counter such distinctions, focusing on the way that even individual acts of meat consumption can be bound up with humanist epistemologies in particular cultural contexts.

Like Haraway, Wolfe is critical of the "massification" of animals that occurs under biocapitalism and renders animals killable with no ethical reflection (5), but he also makes explicit that individual human-animal relations can equally render animals "killable." These arguments come to the fore in his discussion of synthetic meat, where he emphasises that the development of in vitro meat does not provide an ethical resolution (by removing animals from the status of "killable") but is actually "continuous with the technologies and dispositifs that are exercising a more and more finely tuned control over life and 'making live' at the most capillary levels of social existence" (97). Rather than protecting animals from the excesses of the agricultural-industrial economy, therefore, the development of synthetic meat marks an intensification of this system. As Jacob Metcalf reiterates: "The only way to fulfil the 'promises' of cultured meat ... is to assume that it does not come with its own messy sociotechnical apparatus, as if it were possible to engineer out the dangerous worldliness that plagues industrial meat production" (Metcalf, 80), pointing out that "this range of moral action for consumers does little to challenge our food ontologies" (77). 
This feeds into Wolfe's argument about the structures of meat consumption, where he combines his discussion of biopolitics with Derrida's notion of carnophallogocentrism in order to ask: "would many of us find that 'real' meat is 'better,' more authentic, than synthetic meat because it indexes the sovereignty and ipseity of a subject who engages in sacrifice? ... is it what makes meat 'meat"' (97)? In direct contrast to Haraway's analysis of hunting, he then extends this argument to discuss ethical consumerism (such as free range or organic products) and suggests that this combination of carnophallogocentrism and biopolitics helps us to "tease out an important deep-structure of the locavore/'ethical carnivore' phenomenon: the fact that its followers 'do not sacrifice sacrifice"' (97).

Wolfe's argument is thus that meat consumption is bound up with the structures guaranteeing the ipseity of the humanist subject and is contingent on animals being positioned as legitimately "consumable." This structure makes it problematic to dismiss vegan praxis on the basis of being totalitarian, due to revealing the equally totalising structures of meat-eating. What is important, though, is that he combines his articulation of carnophallogocentrism with biopolitical theory in order to overcome criticisms that have been levelled at Derrida's arguments for treating the notion of sacrifice in an overly-general manner (by extending the structures of animal sacrifice in ritualistic contexts to contemporary meat consumption; see de Fontenay, 1-18). This is evident in Wolfe's explicit shift from the rhetoric of sacrifice (as reflected by his aforementioned critique of Agamben's focus on sovereign power designating who can be killed without ethical reflection) in favour of an analysis of the routinised processes of killing that underpin the agricultural-industrial complex. Articulated in a Foucauldian register, carnophallogocentrism thus refers less to the ritualised sacrifice of animals at the behest of the 
autonomous subject, and more to the way that meat consumption feeds into the discourses of the liberal consumer-subject: as a manifestation of the freedom to do (or eat!) whatever this subject wants (as long as it is economically productive). ${ }^{21}$ Conversely, this structure projects veganism as the removal of this choice (as impinging on the consumer-subject's rights), or as just another dietary option and expression of personal choice (as with discourses of ethical consumerism). By combining carnophallogocentrism and biopolitics, however, Wolfe provides conceptual tools with which to unpack the complex relationship between meat consumption and biopolitics.

This paves the way for veganism to be framed not as a totalising practice, but as a form of "affirmative biopolitics." In other words, veganism intervenes in the exertion of biopower by highlighting the biopolitical dimension of meat consumption and denaturalising the irreducible set of human-animal relations that are forged by the practice. The significance of this is that it both reveals the blind-spots of the existing ethical community, which cannot account for the complexity or power dynamic of these relations. What is key is that any new delineation of this community should not be rigid, but create the necessary conditions for further openness and complexity, echoing Wolfe's closing argument: "An affirmative biopolitics need not—indeed, as I have argued cannot—simply embrace 'life' in all its undifferentiated singularity" (104); instead "we must choose [what to include in the ethical community], and by definition we cannot choose everyone and everything at once. But this is precisely what ensures that, in the future, we will have been wrong" (103). In this light, a material practice (such as veganism) that takes a clearly defined ethical position but, in doing so, denaturalises the epistemological structures that support humanist political subjectivities, is perhaps more open than one that seemingly 
"stays with the trouble" but does not create space for identifying, or critically engaging with, the ethical blind-spots that perpetuate humanist norms and values.

\section{Conclusion}

By beginning with an overview of debates between ecofeminism, CAS and animal studies, with a specific focus on the framing of veganism within these fields, I have argued that both ecofeminism and CAS offer a powerful ethical critique of animal exploitation. Through advancing this critique, however, I have illustrated processes through which these criticisms have been marginalised within "mainstream" animal studies due to paradoxically being positioned as both totalising and grounded in individual sentiment. In contrast with this framing, my argument is that both fields contain insights that are valuable in unsettling a more subtle form of anthropocentrism that has emerged in animal studies, but is difficult to challenge due to the influence of posthumanism. This argument provides a counterweight to the negative framing of these perspectives in "mainstream" animal studies as totalising or themselves grounded in concepts with a humanist lineage (such as rights), which has led to the arguments offered by these fields being side-lined.

Vegan praxis has been used as illustrative of these tensions, with veganism's conceptual value being by-passed by influential figures such as Haraway and veganism itself being framed as totalising or grounded in misplaced sentiment. "Mainstream" animal studies' failure to engage with the epistemologically disruptive potential of veganism, in turn, inhibits an interrogation of the equally totalising structures perpetuated by meat consumption, both in supporting humanist epistemologies and in depoliticising the biopolitical configurations of the agricultural-industrial complex. Wolfe's work, however, 
is valuable in countering the marginalisation of critical perspectives within these debates, through foregrounding the structural role of animal consumption in the exertion of biopower and pointing to the radical conceptual significance of veganism. In conclusion, therefore, I argue that a focus on Wolfe's work is vital in opening space for the more productive conversation between posthumanist thought, CAS and ecofeminism that is needed to overcome the increasingly apolitical tendencies emerging within animal studies.

\section{Notes}

${ }^{1}$ This definition draws on Cary Wolfe's characterisation of the origins of animal studies (What is Posthumanism, 99-226) and Sarah Whatmore's analysis of cultural geography's focus on "morethan-human" actors (Whatmore, "Materialist Returns").

${ }^{2}$ The understanding of posthumanism used here is again derived from Wolfe's argument that a truly posthumanist approach should de-stabilise the human/animal distinction, move beyond anthropocentric-humanist ethical frameworks, and challenge the individual "knowing theorist" being positioned as the source of these frameworks (arguing instead for the formation of complex, trans-disciplinary knowledge; Wolfe, What is Posthumanism, 99-126). By humanist epistemologies, I am referring to the series of binary oppositions (such as subject/object, human/animal), that a number of thinkers have argued underpin humanist ethical frameworks and against which the humanist subject is defined. Rosi Braidotti provides a useful overview of how posthumanist theory has been used to denaturalise and contest the binary oppositions that underpin humanist though in The Posthuman [page ref].

${ }^{3}$ While a range of thinkers from CAS have made these criticisms, particularly in relation to Donna Haraway's work, the best examples are Carol Adams's "An Animal Manifesto" and Zipporah Weisberg's "Broken Promises of Monsters".

${ }^{4}$ By "totalising" I mean that these discourses are represented as lacking cultural and contextual specificity, a criticism coming to the fore in feminist and poststructuralist theory in the 1980s, where theorists pointed to the danger of politically progressive discourses themselves becoming normative and marginalising those who did not fit with their ethical paradigm. See Haraway's "Promises of Monsters" for an elaboration of this critique, in relation to the marginalisation of indigenous knowledge. This accusation has been levelled at CAS in overviews of animal studies, which focus on the influence of posthumanist thought, but side-line or misrepresent more critical perspectives due to their perceived preoccupation with "rights". In cultural geography this is evident in Lorimer's, "Multinatural Geographies" and Matthew Wilson et al's "Cyborg Spaces". 
Haraway's own work also fails to engage meaningfully with more critical perspectives, as evidenced her brief engagement with Adams's work in the final chapter of When Species Meet. I have elaborated further elsewhere, on this form of side-lining in Haraway's work itself (see Giraud "Beasts of Burden").

${ }^{5}$ For instance, Steve Best makes clear that CAS was established in explicit opposition to what he sees as the apolitical influence of theory (at the expense of engagement with concrete action) within mainstream animal studies. As touched on above, Weisberg makes this argument in more specific reference to Haraway, as does Carmen Dell'Aversano.

${ }^{6}$ See N. Katherine Hayles' How We Became Posthuman for a more sustained critique of liberal humanism (Hayles, 6). I further develop my arguments about the disruptive potential of activist practices in "Beasts of Burden".

7 Rosi Braidotti's The Posthuman gives a useful overview of posthumanism's use in animal studies.

${ }^{8}$ This critique of veganism appears throughout When Species Meet (particularly p.80) and these arguments will be addressed in more depth subsequently.

9 Adams is significant here, due to her work being influential in both ecofeminist and CAS contexts; her most famous text, The Sexual Politics of Meat, addressing the cultural and epistemological structures that connect the literal use of animal bodies for meat and the cultural representation of women's bodies as meat.

${ }^{10}$ This is not to say that emotion and advocacy are intrinsically problematic, more that they do not conform to the emerging disciplinary norms of animal studies. I develop these arguments in more depth elsewhere, focusing on Haraway's attribution of Adams' veganism to "love", which frames it as an individual choice rather than a critique of the epistemological structures that legitimise exploitation, see Giraud, "Beasts of Burden".

${ }^{11}$ By biopolitical dispositifs I am referring to Foucauldian understandings of the discursive structures and material mechanisms that secure contemporary biopolitics, with a specific focus Wolfe's account of the privileged role of species in sustaining these cultural configurations. This position is also fleshed out in detail by Nicole Shukin (in Animal Capital).

12 This inclusion of animals as biopolitical subjects has also been developed by Tyson E. Lewis, who suggests that inclusion of animals in the political multitude is vital in forging radical forms of resistance to biopower.

13 The Vegan Society website contains an account of the origins of the term: http://www.vegansociety.com/about/history.aspx 
${ }^{14}$ Fleshing out the associations between there binaries and the humanist subject has been a central task of posthumanism, see Katherine Hayles (4) and Rosi Braidotti.

${ }^{15}$ Haraway's use of "exterminism" is made specifically in relation to pedigree dog breeding, in suggesting the abolition of this practice will lead to the "extermination" particular breeds, and calling instead for more ethical reflection on breeding practices. This argument is in defence of criticisms made by thinkers such as Adams, whose "Vegan-Feminist Manifesto" is explicitly critical of Haraway's stance on dog breeding.

${ }^{16}$ As will be discussed subsequently, this is a misrepresentation of CAS and Twine's work in particular (which Lorimer cites as an example).

${ }^{17}$ Here the work of Tim Luke is cited as a Marxist critique of the difficulty in developing a deep ecological ethics that does not draw on humanist logic, whilst Luc Ferry's work illustrates criticisms that have been levelled at deep ecology for prohibiting certain relations with nature.

${ }^{18}$ For elaboration on this line of argument, see Giraud "Boundary Dissolution as Border".

${ }^{19}$ There is not time to go into these debates in depth here, but Haraway's notion of intra-action is derived from Karen Barad's conception of the term (as distinct from inter-action) referring to the way that entities do not ontologically pre-exist one another, but emerge as distinct entities through their relations. This is a step beyond understanding objects as having pre-defined boundaries, then shaping each other through interaction; instead positing that boundaries emerge through these co-shaping relations, or intra-actions: "It is through specific agential intra-actions that the boundaries and properties of the 'components' of phenomena become determinate ... A specific intra-action ... enacts an agential cut ... between subject and object" (Barad, 815). For Barad, the subject/object distinction is not an intrinsic quality of humanity's relation to the world, therefore, but is simply produced via certain intra-actions. The concept of cosmopolitics, derived from Isabelle Stengers, similarly challenges the subject/object relation by undermining the notion of a passive world. For Stengers, a truly cosmopolitical approach to knowledgemaking creates space for whatever is being observed to challenge the pre-existing conceptual frameworks of the observer: requiring epistemological risk. A particularly clear illustration of this is her account of the work of Barbara McClintock in Power and Invention, but a more indepth elaboration on these theories is found in Stengers' Cosmpolitics I and II.

${ }^{20}$ This is particularly the case in the final chapter of When Species Meet, "Parting Bites", as will be discussed subsequently in the essay.

${ }^{21}$ For further elaboration on the relation between the liberal-consumer subject and economic liberalism, see Michel Foucault's Birth of Biopolitics (286). 


\section{Works Cited}

Adams, Carol. "An Animal Manifesto: Gender, Identity and Vegan-Feminism in the TwentyFirst Century." Interview by Tom Tyler. Parallax 12, 1 (1996): 120-128.

Adams, Carol J. The Sexual Politics of Meat: A Feminist-Vegetarian Critical Theory. 10th ed. New York \& London: Continuum, 2008.

Adams, Carol. "Why Feminist Vegan Now?” Feminist Psychology 20, 3 (2010): 302-317.

Agamben, Giorgio. The Open. Stanford: Stanford University Press, 2004.

Barad, Karen. "Posthumanist Performativity: Toward an Understanding of How Matter Came to 'Matter'." Signs 28, 3 (2003): 801-831.

Beisel, Uri. "Jumping Hurdles with Mosquitos." Environment and Planning D: Society and Space 28 (2010): 46-49

Benjamin, Andrew. "Peculiarity and Exceptions: Jews and Animals." South Atlantic Quarterly 107, 1 (2008):

Best, Steve. "The Rise of Critical Animal Studies.” Journal for Critical Animal Studies VIII, IV (2009): 9-52.

Bogost, Ian. Alien Phenomenology. Minneapolis: University of Minnesota Press, 2012.

Braidotti, Rosi. The Posthuman. London: Polity, 2013.

Calerco, Matthew. Zoographies: The Question of the Animal from Heidegger to Derrida. New York: Columbia Press, 2008.

Cuomo, Chris. Feminism and Ecological Communities: An Ethic of Flourishing. London, New York: Routledge, 2008.

Dell'Aversano, Carmen. "The Love Whose Name Cannot Be Spoken: Queering the HumanAnimal Bond." Journal for Critical Animal Studies VIII,1/2 (2010): 73-125.

Esposito, Roberto. Bios. Minneapolis: University of Minnesota Press, 2010.

Foucault, Michel. The Birth of Biopolitics: Lectures at the College de France 1978-1979. New York: Palgrave Macmillan, 2010.

Gaard, Greta. "Ecofeminism Revisited: Rejecting Essentialism and Re-placing Species in a Material Feminist Environmentalism." Feminist Formations 23, 2 (2003): 26-53. 
—."Vegetarian Feminism: A Review Essay." Frontiers 22, 3 (2002): 117-146.

Giraud, Eva. "Beasts of Burden: Productive Tensions Between Haraway and Radical Animal Rights." Theory, Culture and Critique 54, 1 (2013): 102-120.

—. "Boundary Dissolution as Border." Interstitial 1 (2013): forthcoming.

Haraway, Donna. "The Promises of Monsters: A Regenerative Politics for Inappropriate/d Others.” Ed. Lawrence Grossberg et al. Cultural Studies: A Reader. New York: Routledge, 295337.

—. When Species Meet. Minneapolis and London: University of Minnesota Press, 2008.

- "When Species Meet: Staying with the Trouble." Environment and Planning D: Society and Space 28, 1 (2010): 53-55.

- "Species Matters, Humane Advocacy: In the Promising Grip of Earthly Oxymorons." Species Matters. Ed. Marianne DeKoven and Michael Lundblad. New York: Columbia University Press, 2011. 17-26.

Hayles, N. Katherine. How We Became Posthuman. Chicago: University of Chicago Press, 1999.

Kheel, Marti. "Vegetarianism and Ecofeminism: Toppling Patriarchy with a Fork."

Food For Thought. Ed. Steve F. Sapontzis. Amherst, NY: Prometheus, 2004. 327-41.

Lewis, Tyson E. "Swarm Intelligence: Rethinking the Multitude from within the Transversal Commons." Culture, Theory and Critique 51,3 (2010): 223-238.

Lorimer, Jamie. "Multinatural Geographies for the Anthropocene." Progress In Human Geography 36, 5 (2013): 593-692.

Metcalf, Jacob. "Meat Schmeat: Food System Ethics, Biotechnology and Re-Worlding Technoscience." Parallax 19, 1 (2013): 74-87.

Pedersen, Helena. "Release the Moths: Critical Animal Studies and the Posthumanist Impulse." Culture, Theory and Critique 52, 1 (2011) 65-81.

Seager, Joni. "Pepperoni or Broccoli? On the Cutting Wedge of Feminist Environmentalism." Gender, Place \& Culture 10, 2 (2003): 167-174.

Shukin, Nicole. Animal Capital: Rendering Life in Biopolitical Times. Minneapolis and London: University of Minnesota Press, 2009.

Stengers, Isabelle. Power and Invention. Minneapolis: University of Minnesota Press, 1997. 
—. Cosmopolitics I. Minneapolis: University of Minnesota Press, 2010.

—. Cosmopolitics II. Minneapolis: University of Minnesota Press, 2011.

Sturgeon, Nöel. "Considering Animals: Kheel's Nature Ethics and Animal Debates in EcoFeminism." Ethics \& the Environment 14, 2 (2009): 153-162.

Twine, Richard. "Genomic Natures Read Through Posthumanisms." Sociological Review 58, 1 (2010): 175-195.

—. "Intersectional Disgust? Animals and (Eco)feminism." Feminism \& Psychology 20,3 (2010): 497-406.

—. Animals as Biotechnology. London and Washington: Earthscan, 2010.

Weisberg, Z. "The Broken Promises of Monsters: Haraway, Animals and the Humanist Legacy." Journal for Critical Animal Studies. 7, 2 (2009): 21-61.

Whatmore, Sarah "Materialist Returns: practising cultural geography in and for a more-thanhuman world." Cultural Geographies 13, 4 (2006): 600-609.

Wilson, M. et al. "Cyborg Spaces and Monstrous Places: Critical Geographic Engagements with Harawayian Theory." Aether 8a (2011): 42-67

Wolfe, Cary. Animal Rites. Chiacago: University of Chicago Press, 2003.

—. What Is Posthumanism? University of Minnesota Press: Minneapolis, 2010.

-. Before the Law: Humans and Animals in a Biopolitical Frame. Chicago: University of Chicago Press, 2012. 